\title{
Sodium thiophosphate electrolyte thin films prepared by pulsed laser deposition for bulk-type all-solid-state sodium rechargeable batteries
}

\author{
Yusuke ITO ${ }^{1}$, Masahisa KONISHI ${ }^{1}$, Kousuke NOI ${ }^{1}$, Minako DEGUCHI ${ }^{1}$, \\ Akitoshi HAYASHI ${ }^{1}{ }^{\dagger}$ and Masahiro TATSUMISAGO ${ }^{1}$ \\ ${ }^{1}$ Department of Applied Chemistry, Graduate School of Engineering, Osaka Prefecture University, \\ 1-1 Gakuen-cho, Naka-ku, Sakai 599-8531, Japan
}

\begin{abstract}
Sodium rechargeable batteries using earth-abundant raw material sources are more suitable for wide application as compared to lithium batteries. The development of inorganic solid electrolytes with high Na-ion conductivity is indispensable to realize all-solid-state sodium batteries. The sulfide solid electrolyte with cubic $\mathrm{Na}_{3} \mathrm{PS}_{4}$ phase has a high sodium-ion conductivity at room temperature. This research has addressed, for the first time, the preparation of $\mathrm{Na}_{3} \mathrm{PS}_{4}$ electrolyte thin films using pulsed laser deposition, to be applied in bulk-type allsolid-state sodium batteries. The heat-treated $\mathrm{Na}_{3} \mathrm{PS}_{4}$ thin film exhibited a conductivity of $3.5 \times 10^{-5} \mathrm{~S} \mathrm{~cm}^{-1}$ at $25^{\circ} \mathrm{C}$ and the activation energy for conduction was calculated to be $45 \mathrm{~kJ} \mathrm{~mol}^{-1}$. The active material in the form of $\mathrm{NaCrO}_{2}$ particles coated with $\mathrm{Na}_{3} \mathrm{PS}_{4}$ thin film was applied in all-solid-state batteries, which functioned as a sodium secondary battery at room temperature.

(O2018 The Ceramic Society of Japan. All rights reserved.
\end{abstract}

Key-words : Solid electrolyte, Thin film, Sulfide, All-solid-state battery, Sodium battery

[Received January 10, 2018; Accepted March 25, 2018]

\section{Introduction}

In recent times, rechargeable sodium batteries have attracted a great deal of interest as low-cost and sustainable alternatives to lithium batteries, especially in large energy storage devices. ${ }^{1-3)}$ In this context, particularly significant are the serious safety issues that need to be addressed in vehicle electrification, since flammable non-aqueous liquid electrolytes are currently applied in battery packs that are used in EVs. The increased risk of fire and explosion in conventional batteries has raised safety concerns with respect to their wide application. Therefore, the large-scale development of high-safety sodium batteries is urgently required.

Inorganic solid electrolytes can potentially improve the safety and performance of state-of-the-art batteries due to their various advantages such as no leakage, high iontransport number $(\sim 1)$, a wide electrochemical window, and high thermal stability. ${ }^{4)-6)}$ Thus, all-solid-state batteries using inorganic solid electrolytes are considered to be the most promising candidates that can satisfy the following demands: inherent safety due to their nonflammable nature, high energy density and high-power inputs/ outputs, the possibility to obtain a stacked configuration of battery cells in a single package, and compatibility with scalable fabrication processes. ${ }^{7)-10)}$ To date, two types

Corresponding author: A. Hayashi; E-mail: hayashi@ chem.osakafu-u.ac.jp (namely, film and bulk) of all-solid-state batteries have been investigated. Bulk-type batteries with composite electrodes obtained by mixing electrode active material powders and solid electrolyte ones, are suitable for largescale power-related applications. However, conventional powder mixing protocols followed by powder compaction by pressing have not been found to be effective to create ion-conductive pathways in these composite electrodes. This in turn limits the electrochemical performance of bulk-type all-solid-state cells.

The surface modification of the electrode by coating a solid electrolyte is expected to be advantageous to overcome this difficulty, where the microstructure of the electrode can be appropriately designed. Here, it is noteworthy that the exploration of inorganic solid electrolytes with high ionic conductivity is indispensable to obtaining improved cell performance. Sulfide-based solid electrolytes show ionic conductivities that are several orders of magnitude higher than those of oxide materials. Regarding sulfide sodium superionic conductors, the ionic conductivity of $\mathrm{Na}_{3} \mathrm{PS}_{4}$ glass-ceramic electrolyte is reported to be $10^{-4} \mathrm{~S} \mathrm{~cm}^{-1}$ at room temperature. ${ }^{11), 12)}$ The conductivity of $\mathrm{Na}_{3} \mathrm{PS}_{4}$ was increased to $7.4 \times 10^{-4} \mathrm{~S} \mathrm{~cm}^{-1}$ by forming a solid solution with $\mathrm{Na}_{4} \mathrm{SiS}_{4}{ }^{13}$ ) Substituting the anion $\mathrm{S}$ by $\mathrm{Se}\left(\mathrm{Na}_{3} \mathrm{PSe}_{4}\right)^{14)}$ and the cation $\mathrm{P}$ by $\left.\mathrm{Sb}\left(\mathrm{Na}_{3} \mathrm{SbS}_{4}\right)^{15}\right)$ further increased the conductivity of $\mathrm{Na}_{3} \mathrm{PS}_{4}$ to $>10^{-3}$ $\mathrm{S} \mathrm{cm}^{-1}$, which is comparable to that of a liquid electrolyte. Moreover, in sulfide solid electrolytes, densification is readily induced by pressing at room temperature. ${ }^{16), 17)}$ The 
deformability of these electrolytes is also useful in the formation of good interfaces with electrode active materials. Therefore, in view of these superior features, namely, higher conductivity and better deformability, bulk-type allsolid-state batteries using sulfide solid electrolytes have been intensely researched.

Pulsed laser deposition (PLD) is a useful tool to produce high-quality inorganic electrolyte thin films. We have previously reported the preparation of Li-ion conductive electrolyte thin films using PLD. ${ }^{18)}$ We have also used the PLD technique to deposit sulfide electrolytes directly onto particles of active materials such as $\mathrm{LiCoO}_{2}$, which led to an ideal electrode-electrolyte interface and increased the electrochemically active surface area. ${ }^{19), 20)}$ To the best of our knowledge, there have been no reports on the preparation of sodium thiophosphate electrolyte films using a vapor phase process. A nominal composition of $75 \mathrm{Na}_{2} \mathrm{~S}$. $25 \mathrm{P}_{2} \mathrm{~S}_{5}(\mathrm{~mol} \%)$, corresponding to $\mathrm{Na}_{3} \mathrm{PS}_{4}$, was chosen, because this composition has been reported to show the highest ionic conductivity in the $\mathrm{Na}_{2} \mathrm{~S}-\mathrm{P}_{2} \mathrm{~S}_{5}$ system. ${ }^{21)}$

This study examines the morphology, chemical composition, structure and conductivity of $\mathrm{Na}_{3} \mathrm{PS}_{4}$ electrolyte thin films fabricated using PLD. The influence of heat treatment on the morphology, structure, and conductivity of the obtained thin films has been evaluated. Surface modification with $\mathrm{Na}_{3} \mathrm{PS}_{4}$ electrolytes was carried out on the electrode active material. $\mathrm{NaCrO}_{2}$ was selected because of its excellent electrochemical properties as well as due to the simple sample preparation protocol. ${ }^{22), 23)}$ The objective of this research is to elucidate the effect of the formation of an interface between the $\mathrm{NaCrO}_{2}$ electrode and the $\mathrm{Na}_{3} \mathrm{PS}_{4}$ electrolyte on the electrochemical properties as applied to bulk-type all-solid-state cells.

\section{Experimental}

In this paper, the obtained thin films are denoted by their nominal compositions. $\mathrm{Na}_{3} \mathrm{PS}_{4}$ electrolyte thin films were produced by PLD using a $\operatorname{KrF}$ excimer laser $(\lambda=248 \mathrm{~nm}$, LPXPro; Lambda Physik). The pulsed laser energy was $200 \mathrm{~mJ} /$ pulse and the laser frequency was $10 \mathrm{~Hz}$. Pellets of $\mathrm{Na}_{3} \mathrm{PS}_{4}$ were used as the target. $\mathrm{Na}_{3} \mathrm{PS}_{4}$ was prepared by a mechanochemical technique consisting of grinding precursors in a planetary ball mill (Pulverisette 7; Fritsch). The starting materials in the form of crystalline powders with the composition, $75 \mathrm{~mol} \% \mathrm{Na}_{2} \mathrm{~S}$ (99.1\%; Nagao Co. Ltd.) and $25 \mathrm{~mol} \% \mathrm{P}_{2} \mathrm{~S}_{5}(99 \%$; Aldrich Chemical Co. Inc.) were hand-ground; the mixture was then placed in a zirconia $\left(\mathrm{ZrO}_{2}\right)$ vessel (internal volume $45 \mathrm{~mL}$ ) with 500 $\mathrm{ZrO}_{2}$ balls (4 mm in diameter). The mechanochemical reaction was performed for $1.5 \mathrm{~h}$ and the rotation speed of the base disk was fixed at $510 \mathrm{rpm} .{ }^{12)} \mathrm{A}$ Si or a glassy $\mathrm{SiO}_{2}$ substrate was placed at a distance of $7 \mathrm{~cm}$ from the target. All thin films were deposited at room temperature under Ar gas pressure of $5 \mathrm{~Pa}$. Moreover, subsequent heat treatment of the obtained thin films was also conducted in an Ar-filled glove box.

The morphology of the electrolyte thin films on $\mathrm{Si}$ substrates was analyzed using a scanning electron micros- copy (SEM, JSM-6610A; JEOL Ltd.). The chemical compositions of the electrolyte thin films were determined by inductively coupled plasma atomic emission spectroscopy (ICP-AES, SPS7800; Seiko Instruments Inc.) and X-ray photoelectron spectroscopy (XPS). XPS measurements $(\mathrm{Al}-\mathrm{K} \alpha)$ were performed using a spectrometer (K-Alpha; Thermo Fisher Scientific). X-ray diffraction (XRD) measurements $(\mathrm{Cu}-\mathrm{K} \alpha)$ were taken using a diffractometer (Ultima IV; Rigaku Corp.). Differential thermal analysis (DTA) was conducted using a thermal analyzer (Thermo Plus TG8110; Rigaku Corp.) at a heating rate of $10^{\circ} \mathrm{C} \mathrm{min}-1$. Raman spectra of the thin films were obtained using a spectrometer (LabRAM HR-800; HORIBA Ltd.) equipped with a green laser $(532 \mathrm{~nm})$. Electrochemical impedance spectroscopy of the thin films was carried out using an impedance analyzer combined with a dielectric interface (SI 1260 and SI 1296; Solartron Analytical). Comb-like gold electrodes sputtered on $\mathrm{SiO}_{2}$ glassy substrates were used to measure the conductivities parallel to the film surface. The length and cross-sectional area of the comb-like gold electrodes were $5.0 \times 10^{-2} \mathrm{~cm}$ and $8.5 \times$ $10^{-4} \mathrm{~cm}^{2}$, respectively.

$\mathrm{Na}_{3} \mathrm{PS}_{4}$ thin films were deposited for 30 min on $\mathrm{NaCrO}_{2}$ particles; the particles were fluidized using a vibratory system (VIB-FB; Nara Machinery Co. Ltd.) to achieve good adhesion at the electrode-electrolyte interface. A target holder was fixed at the upper side, and a vibratory system was installed directly below to deposit the $\mathrm{Na}_{3} \mathrm{PS}_{4}$ thin films on the $\mathrm{NaCrO}_{2}$ particles. Heat treatment of the $\mathrm{Na}_{3} \mathrm{PS}_{4}$-coated $\mathrm{NaCrO}_{2}$ particles was performed in an Ar-filled glove box. The morphology and composition of the $\mathrm{Na}_{3} \mathrm{PS}_{4}$-coated electrode particles were investigated by SEM using a field-emission electron source (SU8220; Hitachi Ltd.) in combination with energy dispersive X-ray spectroscopy (EDS, EMAX Evoution X-Max; Horiba Ltd.).

All-solid-state $\quad\left(\mathrm{Na}_{15} \mathrm{Sn}_{4} / \mathrm{Na}_{3} \mathrm{PS}_{4} \quad\right.$ glass-ceramic/ $\mathrm{NaCrO}_{2}$ ) cells were constructed to examine the electrochemical performance of $\mathrm{NaCrO}_{2}$ particles coated with $\mathrm{Na}_{3} \mathrm{PS}_{4}$ electrolyte. The active material $\mathrm{NaCrO}_{2}$ was synthesized by solid-state reaction following the previously reported procedure. ${ }^{22)} \mathrm{Na}_{3} \mathrm{PS}_{4}$ glass-ceramic was prepared by mechanical milling followed by heat treatment at $270^{\circ} \mathrm{C}$ for $2 \mathrm{~h}^{12)}$ A working electrode was fabricated by thoroughly mixing $\mathrm{NaCrO}_{2}, \mathrm{Na}_{3} \mathrm{PS}_{4}$ glass-ceramic, and acetylene black (AB) in the weight ratio 4:6:1. $\mathrm{Na}_{15} \mathrm{Sn}_{4-}$ $\mathrm{AB}$ composites used as counter electrodes, were produced by mechanically milling a mixture of $\mathrm{Na}, \mathrm{Sn}$ and $\mathrm{AB}$; the weight ratio of $\mathrm{Na}_{15} \mathrm{Sn}_{4}$ :AB was 20:3. A bilayer pellet consisting of the working electrode $(10 \mathrm{mg})$ and the glassceramic electrolyte $(80 \mathrm{mg})$ was obtained by pressing the two layers under $70 \mathrm{MPa}$ pressure $(\varphi=10 \mathrm{~mm})$; The $\mathrm{Na}_{15} \mathrm{Sn}_{4}-\mathrm{AB}$ composite was placed on the surface with the electrolyte, and a pressure of $360 \mathrm{MPa}$ was applied to the three-layered pellet. The thickness of the working electrode layer and the electrolyte (separator) layer was respectively about 100 and $500 \mu \mathrm{m}$. The pellet was sandwiched between two stainless steel rods, which served also as 
current collectors for both positive and negative electrodes. The all-solid-state cells were tested using a chargedischarge measuring device (BTS-2004; Nagano Co. Ltd.) in the voltage range $2.0-3.5 \mathrm{~V}$ under constant currents in the range $13-64 \mu \mathrm{A} \mathrm{cm}^{-2}$ at room temperature.

\section{Results and discussion}

A cross-sectional SEM image of the $\mathrm{Na}_{3} \mathrm{PS}_{4}$ electrolyte thin film is presented in Fig. 1(a). It is seen that a dense film of the electrolyte with a thickness of ca. $2 \mu \mathrm{m}$ is formed, which adheres quite firmly to the Si substrate. The XRD pattern of the $\mathrm{Na}_{3} \mathrm{PS}_{4}$ thin film is shown in Fig. 1(b). The total absence of diffraction peaks shows that the thin film grown using PLD is amorphous.

The electronic states of sulfur in the film sample were evaluated by $S_{2 p}$ XPS spectra. Figure 1(c) shows the $S_{2 p}$ photoelectron spectra for the $\mathrm{Na}_{3} \mathrm{PS}_{4}$ electrolyte thin film. Prior to measurement, Ar ion-etching for 1, 10, and $20 \mathrm{~min}$ at the etching rate of $10 \mathrm{~nm} \mathrm{~min}^{-1}$ was performed to eliminate surface impurities. The changes in $S_{2 p}$ spectra with increase in Ar ion-etching time corresponding to etching depths of 10,100 , and $200 \mathrm{~nm}$, were monitored to eluci- date the uniformity of the film structure and composition. The main peak at $161.5 \mathrm{eV}$ is assigned to $\mathrm{PS}_{4}{ }^{3-}$ units. Following peak deconvolution, doublet peaks attributed to $\mathrm{S}_{2 \mathrm{p} 1 / 2}$ and $\mathrm{S}_{2 \mathrm{p} 3 / 2}$ originating from non-bridging sulfur are observed. The separation of the $S_{2 p}$ peaks arises due to the spin orbital splitting of the $S_{2 p 1 / 2}$ and $S_{2 p 3 / 2}$ components. These two components are separated by an energy difference of $1.2 \mathrm{eV}$ and the relative intensity ratio is $\left.1: 2 .^{24}\right)$ Furthermore, no apparent difference is observed in the $S_{2 p}$ spectra after each etching process, indicating that the film structure and composition are almost uniform in the vertical direction. The chemical composition of the electrolyte thin film was determined by ICP analysis. The atomic ratio of $\mathrm{Na} / \mathrm{P}$ in the film sample is found to be 3.0, which is in good agreement with the nominal composition.

Figure 1(d) shows the DTA curve of the powder sample, obtained by detaching the $\mathrm{Na}_{3} \mathrm{PS}_{4}$ electrolyte film from the $\mathrm{Si}$ substrate. An endotherm corresponding to a glass transition is observed at around $160^{\circ} \mathrm{C}$, suggesting that the amorphous thin film is in a glassy state. Two exotherms corresponding to crystallization are also observed. After pre-annealing at $160^{\circ} \mathrm{C}$ for $30 \mathrm{~min}$, the subsequent
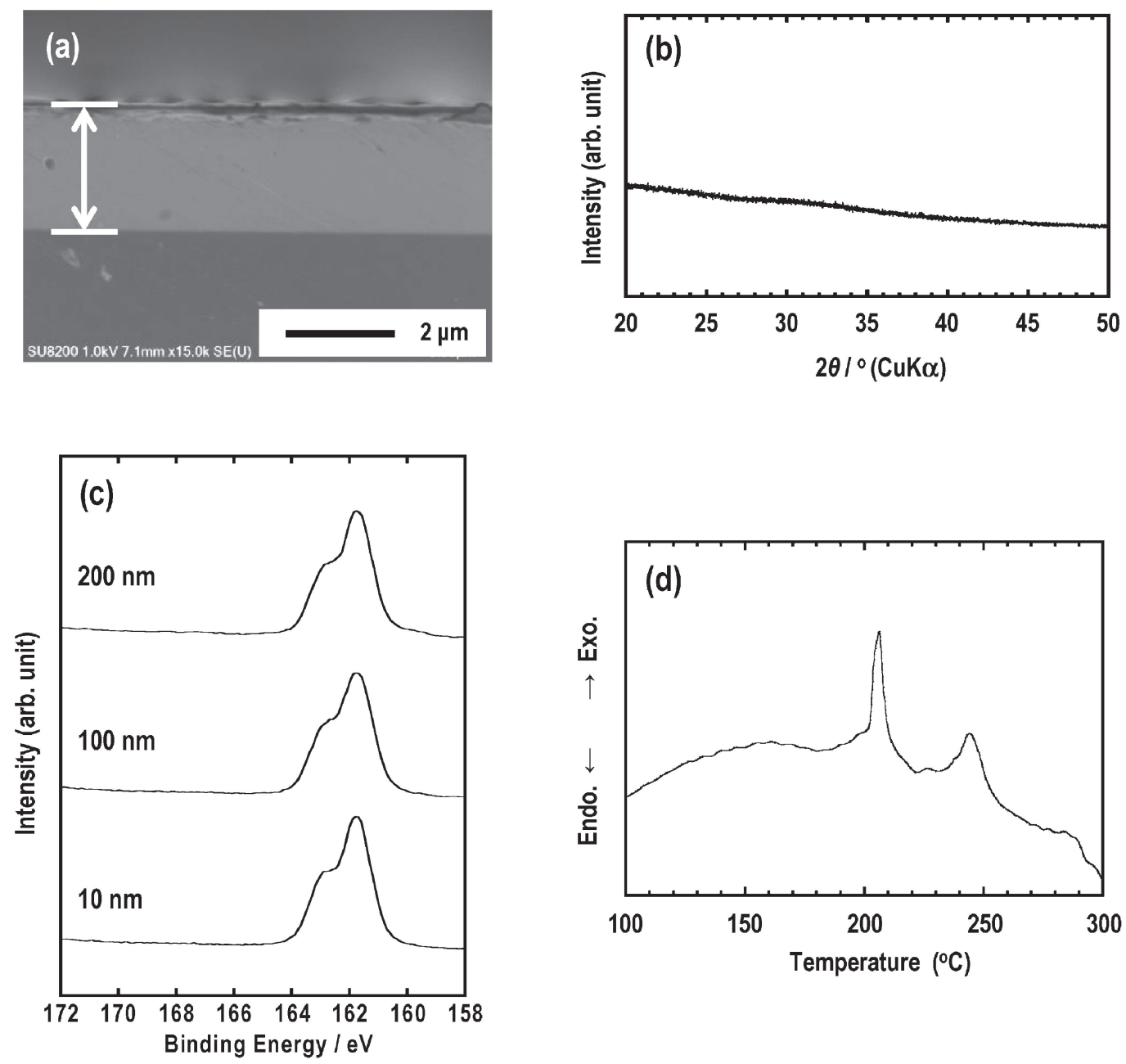

Fig. 1. (a) Cross-sectional SEM image, (b) XRD pattern, (c) $\mathrm{S}_{2 \mathrm{p}}$ photoelectron spectra etched with $\mathrm{Ar}^{+}$ions for 10,100 , and $200 \mathrm{~nm}$ of the $\mathrm{Na}_{3} \mathrm{PS}_{4}$ thin film prepared on Si substrate, and (d) DTA curve of the powder sample obtained by peeling off the film from Si substrate. 

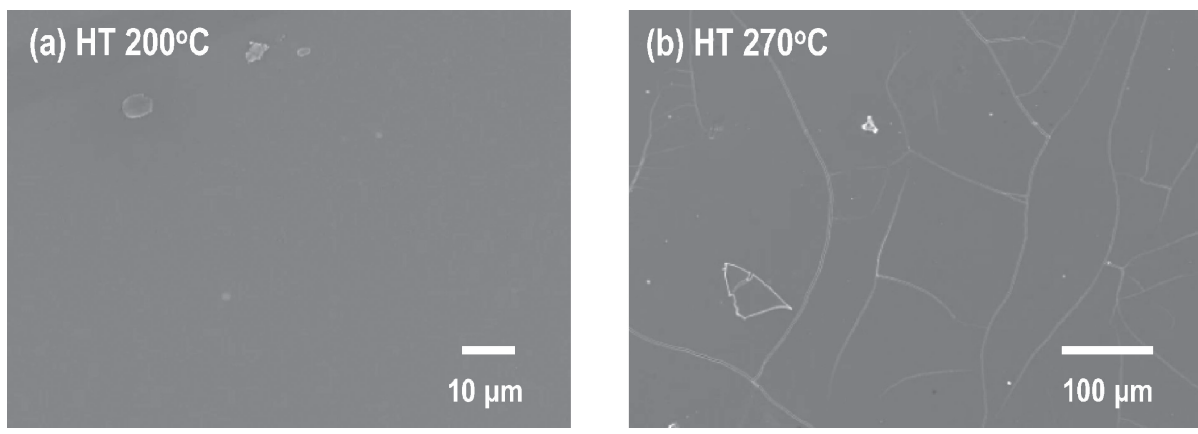

Fig. 2. SEM images of the surface of the $\mathrm{Na}_{3} \mathrm{PS}_{4}$ film prepared by heat treatment (HT) at (a) $200^{\circ} \mathrm{C}$ and (b) $270^{\circ} \mathrm{C}$.
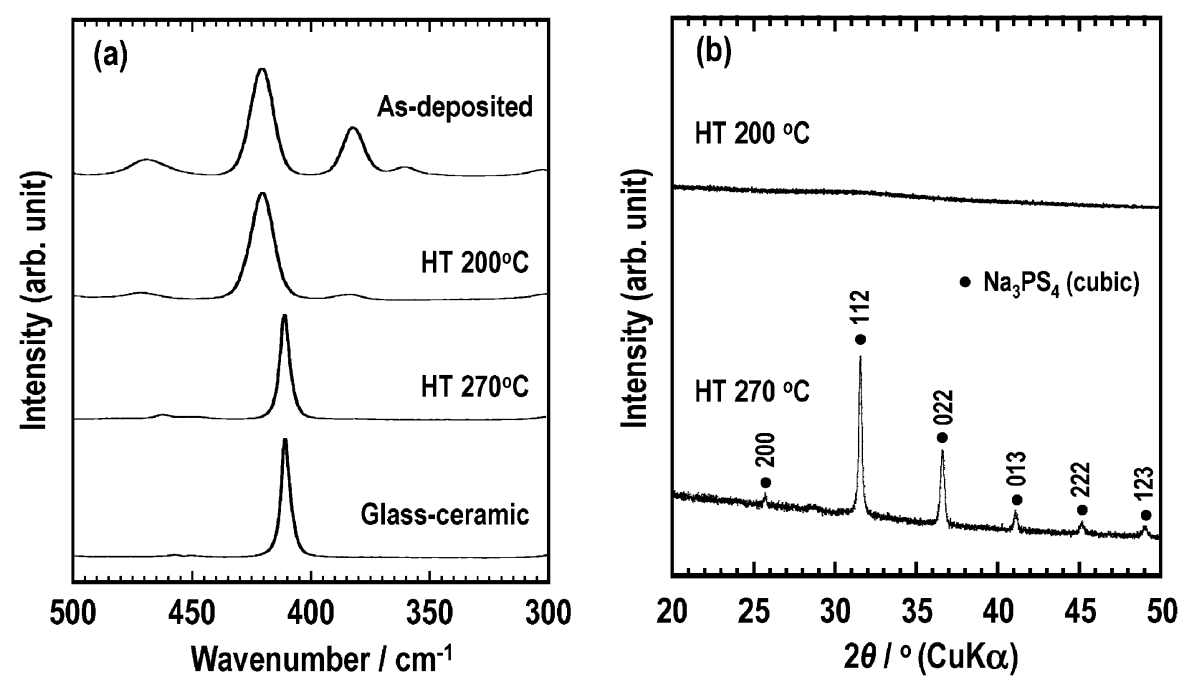

Fig. 3. (a) Raman spectra of the $\mathrm{Na}_{3} \mathrm{PS}_{4}$ films before and after heat treatment at 200 and $270^{\circ} \mathrm{C}$; (b) $\mathrm{XRD}$ patterns of the powder samples obtained by heat treatment at 200 and $270^{\circ} \mathrm{C}$.

heat treatment was conducted for one hour at either $200^{\circ} \mathrm{C}$, or at $270^{\circ} \mathrm{C}$, which are, respectively, around and higher than the crystallization temperature.

This study specifically examines the effect of heat treatment of the obtained thin films on their morphology, structure and conductivity. A comparison of the surface morphology of the film electrolytes heat-treated at (a) $200^{\circ} \mathrm{C}$ and (b) $270^{\circ} \mathrm{C}$ is shown in Fig. 2. While the film (a) has a flat surface without any pinholes, a number of cracks are clearly observed in the film (b). This is probably due to the volume change associated with the crystallization of the glassy thin films. Although cracks are also observed upon heating the $\mathrm{Na}_{3} \mathrm{PS}_{4}$ thin film on alternative substrates such as $\mathrm{SiO}_{2}, \mathrm{Al}_{2} \mathrm{O}_{3}, \mathrm{MgO}$, and stainless steel, the differences in thermal expansion coefficients between the thin film and these substrates do not contribute to crack formation. The smooth surface thus enables the electrolyte film to adhere well to the electrode particles and achieve a good contact.

Figure 3(a) shows Raman spectra of the $\mathrm{Na}_{3} \mathrm{PS}_{4}$ film electrolytes with and without heat treatment at 200 or $270^{\circ} \mathrm{C}$. Peaks at around 385,420 , and $475 \mathrm{~cm}^{-1}$ are observed for the as-deposited thin film. Tachez et al. reported that the bands at 382 and $418 \mathrm{~cm}^{-1}$ can be respectively assigned to $\mathrm{P}_{2} \mathrm{~S}_{6}{ }^{4-}$ and $\mathrm{PS}_{4}{ }^{3-}$ units in lithium thiophosphate glasses. ${ }^{25)}$ The band at $475 \mathrm{~cm}^{-1}$ is attributed to $\mathrm{S}-\mathrm{S}$ bonds in elemental sulfur or in lithium polysulfides. ${ }^{26)}$ Thus, it can be concluded that the as-deposited thin film is composed of $\mathrm{Na}^{+}, \mathrm{PS}_{4}{ }^{3-}, \mathrm{P}_{2} \mathrm{~S}_{6}{ }^{4-}$ and $\mathrm{S}-\mathrm{S}$ bonds. However, the relative intensities of the peaks at 385 and 475 $\mathrm{cm}^{-1}$ against that at $420 \mathrm{~cm}^{-1}$ decrease after heat treatment regardless of the heating temperature. Bischoff et al. have reported the observation of a band at $410 \mathrm{~cm}^{-1}$ in crystallized samples of $\mathrm{Na}_{3} \mathrm{PS}_{4}$ glasses. ${ }^{27)}$ The same band is observed in the $\mathrm{Na}_{3} \mathrm{PS}_{4}$ glass-ceramic in our case, which can be assigned to the $\mathrm{PS}_{4}{ }^{3-}$ unit in crystalline $\mathrm{Na}_{3} \mathrm{PS}_{4}$. We infer therefore, that after heat treatment at $200^{\circ} \mathrm{C}$, the crystallization of the thin film is incomplete and the glassy matrix is preserved. In contrast, heat treatment at temperatures higher than the crystallization temperature brings about a structural rearrangement to precipitate the crystalline phase. Therefore, the thin film heat-treated at $270^{\circ} \mathrm{C}$ is considered to be mainly composed of $\mathrm{Na}^{+}$and $\mathrm{PS}_{4}{ }^{3-}$, which is comparable to the structural units corresponding to the nominal composition.

Figure 3(b) shows XRD patterns of $\mathrm{Na}_{3} \mathrm{PS}_{4}$ film electrolytes heat-treated at 200 and $270^{\circ} \mathrm{C}$. No clear diffraction peaks are observed in the XRD pattern of the thin film 

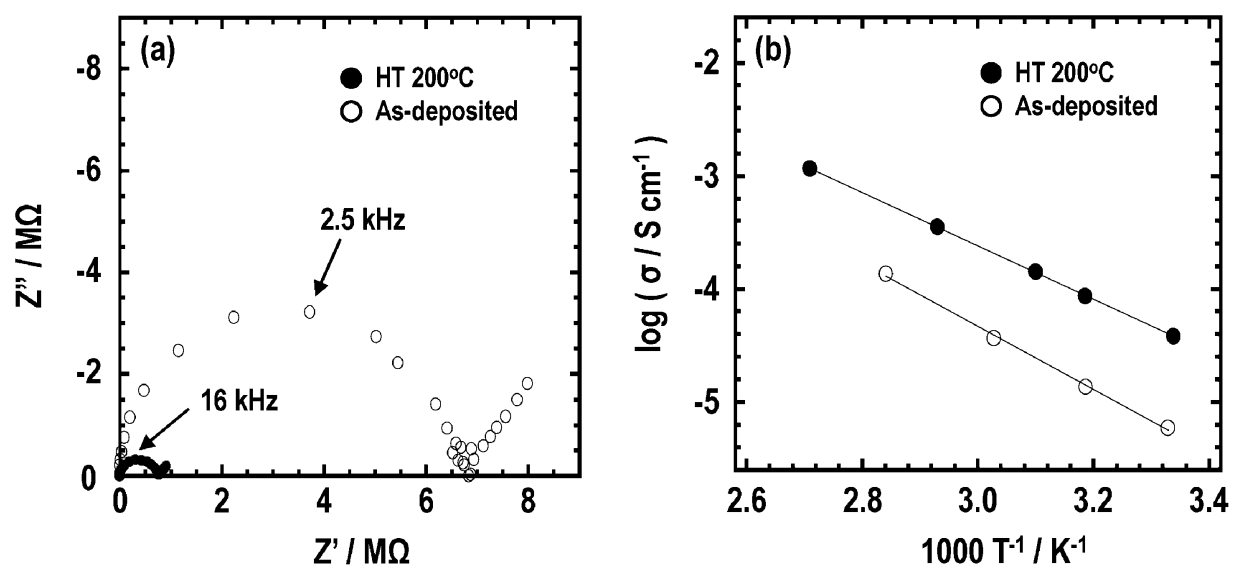

Fig. 4. (a) Complex impedance plots and (b) temperature dependence of ionic conductivity of the thin films with and without heat treatment at $200^{\circ} \mathrm{C}$.
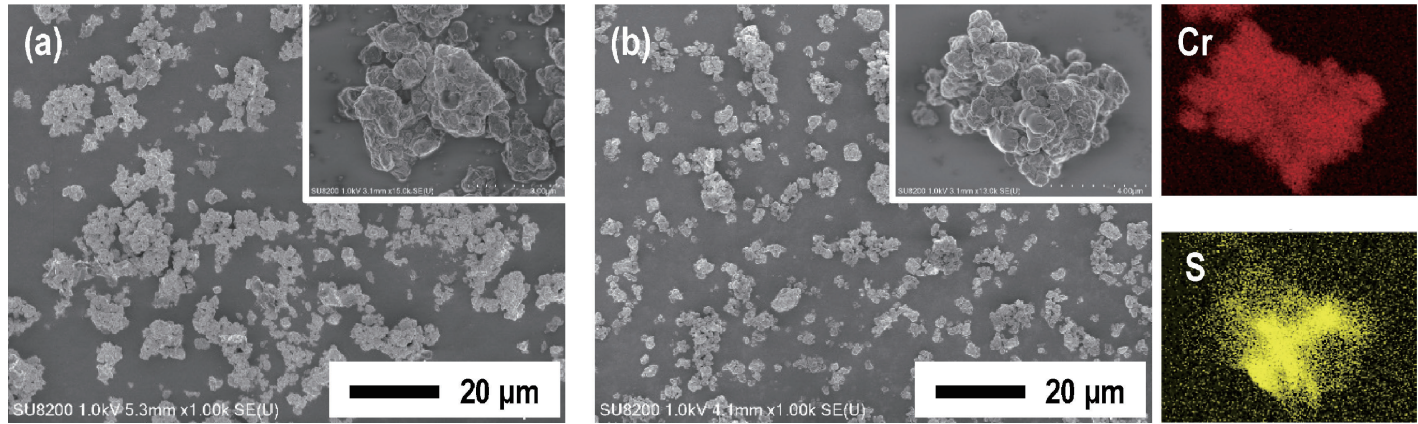

Fig. 5. SEM images of $\mathrm{NaCrO}_{2}$ particles (a) before and (b) after $\mathrm{Na}_{3} \mathrm{PS}_{4}$ electrolyte-coating and subsequent heat treatment at $200^{\circ} \mathrm{C}$. EDX maps of elemental $\mathrm{Cr}$ and $\mathrm{S}$ are also shown for the samples after electrolyte coating on $\mathrm{NaCrO}_{2}$ (b).

heat-treated at $200^{\circ} \mathrm{C}$, which is probably due to its low crystallite size, which is below the detection limit of the XRD instrument. In contrast, diffraction peaks assigned to the cubic $\mathrm{Na}_{3} \mathrm{PS}_{4}$ single phase are observed in of the diffraction pattern of the thin film heat-treated at $270^{\circ} \mathrm{C}$. Transmission electron microscope studies on the heattreated film electrolytes are currently in progress to elucidate the size and distribution of the precipitated crystalline phases, and detailed results will be reported in the near future.

Ionic conductivities of $\mathrm{Na}_{3} \mathrm{PS}_{4}$ electrolyte thin films were measured using comb-like gold electrodes as ionblocking electrodes. For the film samples heat treated at $270^{\circ} \mathrm{C}$, impedance measurements could not be carried out due to their surface morphology. Figure 4(a) shows complex impedance plots of the as-deposited thin film and that heat-treated at $200^{\circ} \mathrm{C}$. A large semicircle followed by a straight line was observed for the thin films, suggesting that both thin films are ion conductors. The resistance of the semicircle, corresponding to bulk resistance, decreases considerably after heat treatment at $200^{\circ} \mathrm{C}$. The temperature dependences of ionic conductivities for the as-deposited and heat-treated thin films are shown in Fig. 4(b). It is seen that the data are in accordance with the Arrhenius law, which means that the activation energy for ionic conduction can be calculated from the slope of the plots. The ionic conductivities of the as-deposited and heat-treated films at $25^{\circ} \mathrm{C}$ are $4.8 \times 10^{-6}$ and $3.5 \times 10^{-5}$ $\mathrm{S} \mathrm{cm}^{-1}$, and the activation energies for ionic conduction are calculated to be 53 and $45 \mathrm{~kJ} \mathrm{~mol}^{-1}$, respectively. The heat-treated thin film thus exhibits higher ionic conductivity and lower activation energy than the as-deposited thin film. Although diffraction peaks were not clearly observed in the XRD pattern of the heat-treated film, we speculate that the precipitation of the cubic $\mathrm{Na}_{3} \mathrm{PS}_{4}$ phase leads to a higher ionic conductivity, and the glassy matrix with small crystals is expected to retain a certain deformability in the electrolyte layer coated on the electrode particles. ${ }^{19)}$ Therefore, in the following, heat treatment for $\mathrm{Na}_{3} \mathrm{PS}_{4}$-coated $\mathrm{NaCrO}_{2}$ particles was performed at $200^{\circ} \mathrm{C}$.

Figure 5 shows SEM images of $\mathrm{NaCrO}_{2}$ particles (a) before and (b) after the $\mathrm{Na}_{3} \mathrm{PS}_{4}$ electrolyte-coating and subsequent heat treatment at $200^{\circ} \mathrm{C}$. EDS elemental mapping images of chromium and sulfur confirm the presence of the active material and the electrolyte-coating layer, respectively. There is no difference in the surface morphology of the $\mathrm{NaCrO}_{2}$ particles, as demonstrated in Fig. 5. In this study, a vibrator system was incorporated inside the PLD chamber during the electrolyte deposition so as to enable the formation of electrolyte coatings without the aggregation of the active material particles. Nevertheless, from the point of view of process engineering, applying this 

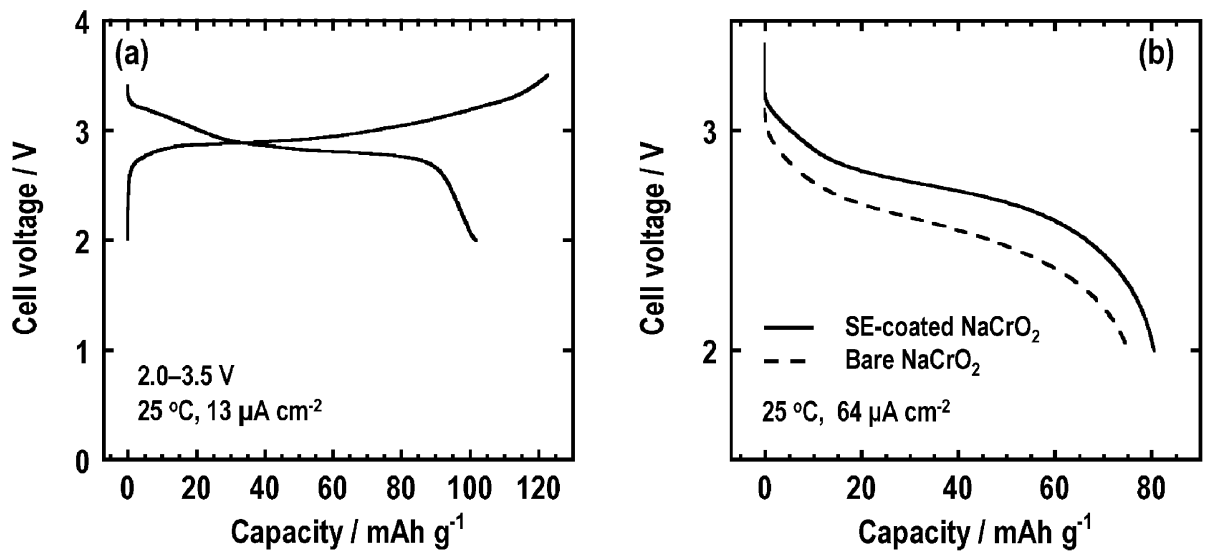

Fig. 6. (a) Initial charge-discharge curve of all-solid-state cells using the $\mathrm{Na}_{3} \mathrm{PS}_{4}$ electrolyte-coated $\mathrm{NaCrO}_{2}$ particles with heat treatment at $200^{\circ} \mathrm{C}$ and (b) discharge curves of the all-solid-state cells with and without electrolyte-coated $\mathrm{NaCrO}_{2}$. The electrolyte-coated one was heat-treated at $200^{\circ} \mathrm{C}$ in advance.

system may not be as efficient to achieve coverage of larger surfaces as solution-processed coatings. ${ }^{9), 15)}$ Although the vapor phase coating protocol is not yet optimized, in this work, we have focused mainly on the effect of electrolyte coating on the charge and discharge properties.

The initial charge-discharge curves of the all-solid-state cells using $\mathrm{Na}_{3} \mathrm{PS}_{4}$ electrolyte-coated $\mathrm{NaCrO}_{2}$ particles heat treated at $200^{\circ} \mathrm{C}$ are shown in Fig. 6(a). Measurements were taken at a current density of $13 \mu \mathrm{A} \mathrm{cm}^{-2}$ at $25^{\circ} \mathrm{C}$. The cell fabricated using $\mathrm{Na}_{3} \mathrm{PS}_{4}$-coated $\mathrm{LiCoO}_{2}$ particles shows a discharge capacity of $102 \mathrm{mAh} \mathrm{g}^{-1}$, which is almost the same or slightly lower than that obtained for a liquid-electrolyte cell. ${ }^{22)}$ Figure 6(b) shows a comparison of the discharge curves of the all-solid-state cells with and without electrolyte-coated $\mathrm{NaCrO}_{2}$. Measurements were performed at a current density of $64 \mu \mathrm{A} \mathrm{cm}^{-2}$ at $25^{\circ} \mathrm{C}$. Both electrolyte-coating and subsequent heat-treatment are found to be effective to form Na-ion conductive pathways to the $\mathrm{NaCrO}_{2}$ particles. In a conventional cathode configuration, sodium-ion transfer between the active material and the solid electrolyte occurs at a point contact at the interface, whereas in the presence of electrolyte coatings, a wider contact area with the $\mathrm{NaCrO}_{2}$ particles is achieved. As a result, the ionic resistance within the composite electrodes is lower, which results in the high voltage profile observed in the discharge curves. Prior surface coating of oxide thin-films on $\mathrm{NaCrO}_{2}$ will improve cell performance by decreasing electrode-electrolyte interfacial resistance; such a behavior has been reported in all-solid-state cells with sulfide electrolytes. ${ }^{7)}$ Increasing the conductivity of the sulfide coating layers leading to sufficient ion conduction pathways can also be effective in increasing the cell capacity; we will address these issues in a future work.

\section{Conclusions}

A dense amorphous thin film of $\mathrm{Na}_{3} \mathrm{PS}_{4}$ solid electrolyte was prepared using the PLD method. Raman and XPS measurements revealed that the as-prepared thin-film had a local structure to similar to the $\mathrm{Na}_{3} \mathrm{PS}_{4}$ electrolyte prepared via mechanochemical methods. The conductivity of the electrolyte film was increased by heat treatment at $200^{\circ} \mathrm{C}$; the heated $\mathrm{Na}_{3} \mathrm{PS}_{4}$ film exhibited a conductivity of $3.5 \times$ $10^{-5} \mathrm{~S} \mathrm{~cm}^{-1}$ at $25^{\circ} \mathrm{C}$ and the activation energy for conduction was calculated to be $45 \mathrm{~kJ} \mathrm{~mol}^{-1}$. The surface coating of $\mathrm{Na}_{3} \mathrm{PS}_{4}$ on the particles of the active material $\mathrm{NaCrO}_{2}$ was performed by PLD and the prepared $\mathrm{Na}_{3} \mathrm{PS}_{4}$-coated $\mathrm{NaCrO}_{2}$ was applied in all-solid-state sodium cells. The surface coating of $\mathrm{Na}_{3} \mathrm{PS}_{4}$ was effective in improving the reversible capacity of the $\mathrm{Na}_{15} \mathrm{Sn}_{4} / \mathrm{Na}_{3} \mathrm{PS}_{4} / \mathrm{NaCrO}_{2}$ cells by increasing $\mathrm{Na}^{+}$ion conduction pathways in the $\mathrm{NaCrO}_{2}$ electrode layer.

\section{References}

1) K. B. Hueso, M. Armand and T. Rojo, Energy Environ. Sci. 6, 734-749 (2013).

2) N. Yabuuchi, K. Kubota, M. Dahbi and S. Komaba, Chem. Rev., 114, 11636-11682 (2014).

3) D. Larcher and J. M. Tarascon, Nat. Chem., 7, 19-29 (2015).

4) M. Tatsumisago and A. Hayashi, Int. J. Appl. Glass Sci., 5, 226-235 (2014).

5) Y. Zhu, X. He and Y. Mo, ACS Appl. Mater. Interfaces, 7, 23685-23693 (2015).

6) J. C. Bachman, S. Muy, A. Grimaud, H. H. Chang, N. Pour, S. F. Lux, O. Paschos, F. Maglia, S. Lupart, P. Lamp, L. Giordano and Y. S. Horn, Chem. Rev., 116, 140-162 (2016).

7) K. Takada, Acta. Mater., 61, 759-770 (2013).

8) Y. Kato, S. Hori, T. Saito, K. Suzuki, M. Hirayama, A. Mitsui, M. Yonemura, H. Iba and R. Kanno, Nat Energy, 1, 16030 (2016).

9) D. H. Kim, D. Y. Oh, K. H. Park, Y. E. Choi, Y. J. Nam, H. A. Lee, S. M. Lee, S. M. Lee and Y. S. Jung, Nano Lett., 17, 3013-3020 (2017).

10) H. Gao, L. Xue, S. Xin, K. Park and J. B. Goodenough, Angew. Chem. Int. Edit., 56, 5541-5545 (2017).

11) A. Hayashi, K. Noi, A. Sakuda and M. Tatsumisago, Nat. Commun., 3, 856 (2012).

12) A. Hayashi, K. Noi, N. Tanibata, M. Nagao and M. Tatsumisago, J. Power Sources, 258, 420-423 (2014).

13) N. Tanibata, K. Noi, A. Hayashi and M. Tatsumisago, RSC Adv, 4, 17120-17123 (2014). 
14) L. Zhang, K. Yang, J. Mi, L. Lu, L. Zhao, L. Wang, Y. Li and H. Zeng, Adv. Energy Mater., 5, 1501294 (2015).

15) A. Banerjee, K. H. Park, J. W. Heo, Y. J. Nam, C. K. Moon, S. M. Oh, S. T. Hong and Y. S. Jung, Angew. Chem. Int. Edit., 55, 9634-9638 (2016).

16) A. Sakuda, A. Hayashi and M. Tatsumisago, Sci. Rep., 3, 2261 (2013).

17) M. Nose, A. Kato, A. Sakuda, A. Hayashi and M. Tatsumisago, J. Mater. Chem. A, 3, 22061-22065 (2015).

18) Y. Ito, A. Sakuda, T. Ohtomo, A. Hayashi and M. Tatsumisago, J. Ceram. Soc. Jpn., 122, 341-345 (2014).

19) Y. Ito, M. Otoyama, A. Hayashi, T. Ohtomo and M. Tatsumisago, J. Power Sources, 360, 328-335 (2017).

20) Y. Ito, S. Yamakawa, A. Hayashi and M. Tatsumisago, J. Mater. Chem. A, 5, 10658-10668 (2017).

21) K. Noi, A. Hayashi and M. Tatsumisago, J. Power
Sources, 269, 260-265 (2014).

22) S. Komaba, C. Takei, T. Nakayama, A. Ogata and N. Yabuuchi, Electrochem. Commun., 12, 355-358 (2010).

23) C. Y. Yu, J. S. Park, H. G. Jung, K. Y. Chung, D. Aurbach, Y. K. Sun and S. T. Myung, Energy Environ. Sci., 8, 2019-2026 (2015).

24) Y. Wang, T. Matsuyama, M. Deguchi, A. Hayashi, A. Nakao and M. Tatsumisago, J. Ceram. Soc. Jpn., 124, 597-601 (2016).

25) M. Tachez, J. P. Malugani, R. Mercier and G. Robert, Solid State Ionics, 14, 181-185 (1984).

26) T. Ohtomo, F. Mizuno, A. Hayashi, K. Tadanaga and M. Tatsumisago, Solid State Ionics, 176, 2349-2353 (2005).

27) C. Bischoff, K. Schuller, M. Haynes and S. W. Martin, J. Non-Cryst. Solids, 358, 3216-3222 (2012). 